\title{
Relationship Between Regional Community Vulnerability and Climate Change
}

\author{
Dr. Anil Kumar Palakodeti \\ Urban Environmental Planner, India
}

\begin{abstract}
: "thawing of permafrost, later freezing and earlier breaking-up of ice in rivers and lakes, pole-ward and attitudinal shifts in the range of variety of plants and flowers, earlier flowering of trees, the emergence of insects and egg-laying of birds..." (MacMichael, 2003, pg. 270). This is the present scenario with the proliferating changes across the world. The current paper presents the adaptive and mitigative measures to address these impact of climate change on the regions.
\end{abstract}

Keywords: Climate change, Regional impacts, Adaptive measures, Mitigative measures, Cost-benefits

\section{Introduction}

The change in climatic conditions has significant effect on third world-nations rather than first and second world nations. These changes are both in temperatures and precipitations (World Bank, 2009). These changes have considerable catastrophic influence both on economic (agriculture, transportation, entrepreneur, infrastructure, energy, trade and commerce) and social dimensions from global to local level communities. Climate change is not fixed to certain period of intervals but, it is extended to over decades. Transformations that occur in climate since origin of the earth and of human are not uncommon and these can be evidenced with the records of tree rings and ice core layers. And these changes are the results of not only the internal climate systems but also the result of external natural and anthropogenic factors (MacMichael, 2003).

All countries across the world are vulnerable to climate change for different reasons. But the sensitivity is quite high or in other words, the adaptive capacity of developing and low developed countries is very low. And this would be the result of following driving forces of vulnerability to climate change: (a) the case of sub-Saharan Africa is the land of deserts and poor infrastructure; (b) the Eastern Europe and Central Asia being driven by poor management of environment and infrastructure facilities and managements; (c) Latin America and Caribbean, which has a high rate of threats to ecosystems; (d) Middle East and North Africa's water resources are vulnerable; (e) South Asia is the land for degraded natural resources and high rates of populations and poverty (World Bank, 2010). Thus, all these acts as catalyst to make effects of climate change worse.

Therefore, addressing these immense problems would require strengthening the mitigation and adaptation of vulnerabilities with global solutions tailoring to local implementations with world-wide co-operation beyond borders in-terms of offsetting climate change costs, catalyzing the opportunities and managing risks as a part of development process with wide range of climate change sensitive development projects (World Bank, 2009).

\subsection{Adaptation}

The present rate of increase in carbon levels in atmosphere has significant increase of about $2{ }^{\circ} \mathrm{C}$ each year and continues to increase even after curbing down the carbon levels. Hence, adaptation with global integrated planning processes and local participation, infrastructure developments, preparedness programs, widening awareness, advanced technologies and practices in different sectors and communities focusing nature and costs to cope the changing temperatures and precipitation patterns in present conditions of unpredicted economy conditions, competing needs and limited resources which require huge investments are upmost important (World Bank, 2009).

\subsection{Mitigation}

The ground reality of increasing air and water temperatures, with more extreme catastrophic weather conditions, increased the risk of floods, droughts, storms, lower agricultural production and demand in water supply resulted in population displacements and migrations. With the increasing per-capita energy usage and emission rates resulted in increase in greenhouse gases in the atmosphere due to larger share of populations and increasing competition in global economy (World Bank, 2009). Hence, there is urgent need to mitigate this globally increasing temperatures by focusing on low-carbon growth measures, effective sustain transport facilities, changing land-use patterns and improving agriculture and sustainable forestry techniques which primarily address the developments, economic and environmental issues.

\section{Vulnerabilities due to Climate Change}

The vulnerabilities to climate change are the possible dimensions to which change in climate that threaten a system or otherwise it is a function of system's disclosure, sensitivity and adaptive capacity. And these vulnerabilities can be classified into agriculture ecosystems, forest ecosystems, grassland/ livestock, water resources, coastal resources, fisheries, wildlife ecosystems, and human. There are many aspects that influence these vulnerabilities. For instance, fragile and hazardous locations, rapid population growth, increasing migration trends, poverty and hunger, poor health conditions, low level of education, gender 
inequalities, lack of access to basic services and resources, limited technological means and lack of effective governments are some of the key vulnerabilities to climate change.

\subsection{Climate change impact at Regional Level}

The most challenging danger that the present communities encounter is drastic climate change, which has an enormous effect on all actors, elements and aspects of our World. And these conditions are often analyzed in-terms of environmental, economic and social issues (Hansjiirgens, 2008). One of the most disturbing causes for the climate change issues is changes in the composition of atmosphere. Statistics show evidence that there is an increasing concentration of greenhouse gasses such as carbon-di-oxide, methane, nitrous-oxide and chloro-floro-carbons in the atmosphere (due to anthropogenic changes) which act as opaque layers to the terrestrial infrared radiations tending to increase the earth's surface temperatures (Pearman, 1988). Hence, any changes that tend to increase the levels of greenhouse gasses in the atmosphere results in global climate change, acid rains, ozone depletion and many more drastic effects, for instance, Antarctic ozone-hole.

Historical studies also showed that there were widespread disasters and diseases, social isolations, loss of soil fertility and biodiversity and freshwater supplies and increase in regional migrations in response to climate changes (MacMichael, 2003). Since ice-age to the present modernage, communities had long standing experience changing climate cycles. On the other hand, there are global variations due to local actions.

\subsubsection{Climate change and Sea-level rise}

It is now evidence that increasing concentration of green gases in atmosphere resulting from human activities, leading to global warming resulting in increase in earth's average surface temperatures consequently in an expansion of sea water also known as steric effect (Pearman, 1988). In addition, there are many snowfields, ice-glaciers and sheets melting into the seawater, resulting in rise of sea-levels. Estimations show that there would be one meter rise in global sea-level/ year 2140 with global increase of $0.4^{\circ} \mathrm{C}$ in mean temperature resulting in 10 to $15 \mathrm{~mm}$ rise in sea level based on the analysis of tide gauge records (Pearman, 1988). There are many other indicators that signify rise in sea level, namely, cliff recession, beach erosion, lagoons and estuaries, marshlands, coral reefs, marine organisms which occupy different layers in the sea water and upon close observation over period, alteration in the levels can be observed (Pearman, 1988).

\subsubsection{Case Study: Australia}

\section{a) Background}

Australia is having world's largest of about $70000 \mathrm{~km}$ open coastline and $12000 \mathrm{~km}$ of equal magnitude islands surrounding and wide range of wetlands prone to sea level rises. The vertical rise which is permanent and the horizontal rise vary from place to place around the coastal line. Since there would be permanent rise in sea water levels, periodic oscillation on the raised sea levels will have more extending inundation and influence on the coastal areas. The frequency, range of inundation and magnitude of varied predictable tides varies along the coastal lines with wide range of threats to different parts of Australian coasts; communities and human (Pearman, 1988).

It is estimated that there would be rise of 0.2 to $1.4 \mathrm{~m}$ in the sea-level over next 40 years affecting wide range of social functions such as residential, commercial, recreational, exports and imports, transportation and other economic activities and natural conservatives of Australian coast. But, conventionally, coastal management of Australia was taken up by local government and affected groups which was initially responsible to State Government with low level of participation from local communities. Many coastal management tools such as integrated land-use policies, impact assessments, and preparedness plans were in play to tackle the catastrophic disaster of raised sea levels or lessen the worse impacts (Pearman, 1988). It is clear that irrespective of the greenhouse gases in atmosphere, coast line of Australia is still encounters threat due to wide range of Human activities such as encroachments into the catchment areas, waste disposal, excavations that result in the erosion of the coastal lines of Australia is $0.5 \mathrm{~m}$ more than the average global sea level rise/ year (Pearman, 1988).

Besides this, there is tremendous increase in population of additional 11 to 15 million is estimated to enter into metropolitan and surrounding provinces which would result in wide range of socio-economic functions, which influence the fragile coastal Australia (Pearman, 1988). Coastal Australia also experiences the effects due to change in vegetation, run-off and different land-uses patterns in these areas (Pearman, 1988).

Summing up the impact of climate change on Australian coastal zones, with primary changes in carbon-di-oxide concentrations resulting in temperature rise, led to temperature rise in sea, transformation in water cycles; this resulted in net rise in sea levels, changes in intensity and frequency of rainfall and occurrence of disasters. Eventually, there was increase in rainwater run-off, sediment loads, coastal erosions, penetrations of salt water into ground water tables. Consequently, there will be huge loss and proper functioning of coastal ecosystems and also has a negative impact on human livelihoods and economic activities.

\section{b) Key Vulnerabilities}

The key vulnerabilities of coastal areas of Australia are Human settlements, coastal rivers and lakes, catchment areas, ground water; water-shed areas, coastal wildlife, flora and fauna, vegetation, low-lying areas, infrastructure services and facilities, livelihoods and socio-economic activities such as recreation, and import - export business.

\section{c) Possible Mitigation and Adaptive measures}

The adverse impact of the sea level rise in these coastal areas can thus be avoided or reduce the impacts/ loss with the following adaptive/ mitigative measures.

- The design of new - infrastructure and upgrading the existing one with an estimations and assumptions of future sea levels. 
- Creating environmentally - sound drainage systems that can also withstand the pressure of increasing population as well as the pressure of raised sea levels.

- Coastal planning and management should be integrated with land-use plan and policy framework.

- Advanced technologies and land management practices should be part of regional planning.

- Development and application of advanced technologies and methods in impact assessments, infrastructure and development projects.

- Involvement of local communities and affected groups into planning process with active support from state and central.

- Preparedness and awareness programs should be planned as a part of coastal management within the policy framework by local and affected groups.

- Effective sustainable transportation facilities.

- Low carbon developments.

- Changing land-use patterns.

- Advanced agriculture and forestry techniques.

\subsubsection{Climate Change on Human Health}

The good health of the population is the result of stable and proper functioning of the life support systems (include global climate systems) of the world, which is hardly being recognized by the current urbanized trends, lifestyle and attitudes of people. And this climate support system is being threatened by the proliferating human population and economic activities. There is significant effect of climate change's environmental hazard on human health from both local and global environmental exposure (MacMichael, 2003).

The health impact of population to some extent is advantageous due to these global climate changes. For instance, it would lessen the mosquitotransmitted diseases in increased temperatures. But, these changes in the climate conditions have more of adverse effects on community in postindustrial period and as well in the predated written history (MacMichael, 2003). Hence, it can be stated that human health and diseases are linked to climate. The web of interactions between nature, climate and human societies is being influenced by any change in these three spheres.

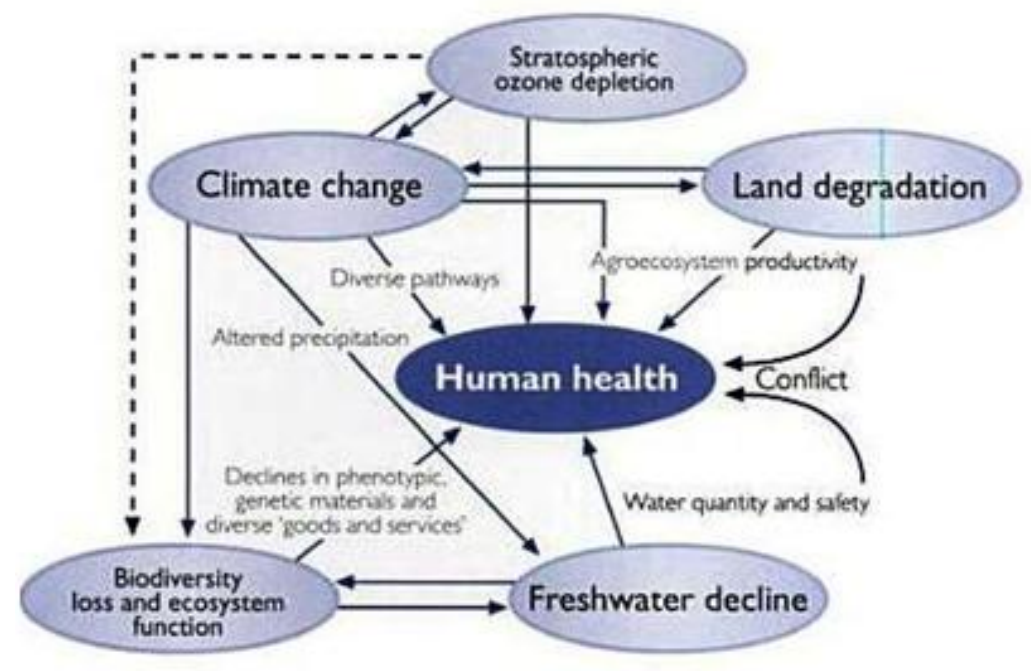

Figure 1: Interrelationship between global environment and human health (MacMichael, 2003)

In many of the European countries during $19^{\text {th }}$ century, the intakes of calories were less than 2000 calories, led to malnutrition and were easily prone to diseases and lessening the life expectancy. Catalyzing these problems with famine conditions periodically resulted in population loss drastically. For example, Tuscany has been recorded 100 years of famine. But these disasters are not just alone due to climate extreme conditions but also influenced by social and political factors (MacMichael, 2003).

The influence of climate change on human health has variation in complexity, scale, location and the susceptibility of population. The following figure show the impacts of climate change on human health:

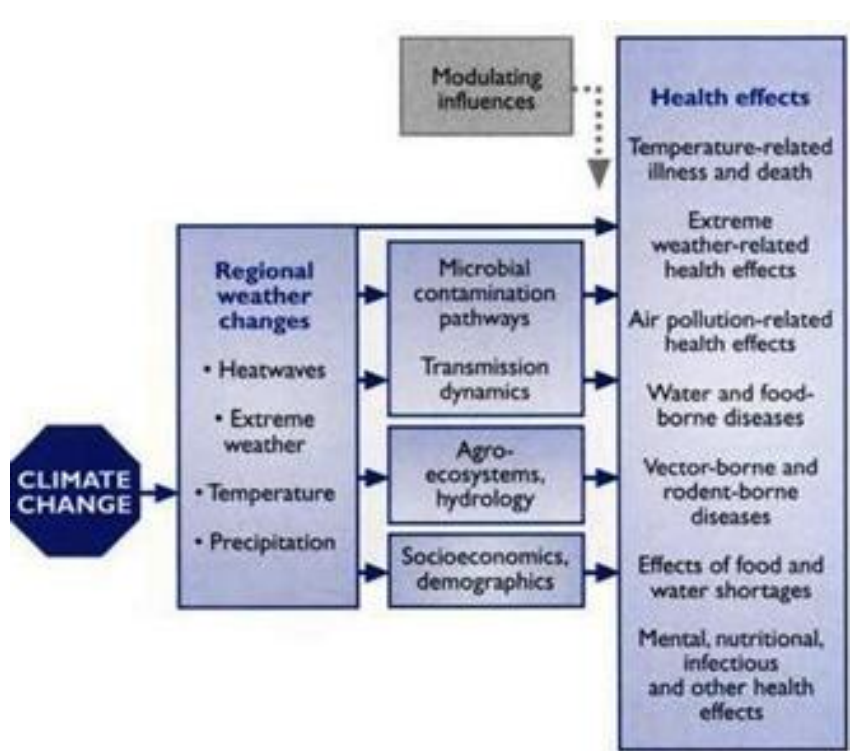

Figure 2: Potential health impacts of climate change (MacMichael, 2003) 
The impact on health is direct exposure to increased weather extremes such as heat waves and cold winters, which results in extreme weather events such as droughts and floods, production of air and water pollutants. But it is uncertain in all the aspects of intensity, frequency, locality and target groups. Alternatively, these changes have significant indirect effect of greater magnitude with transmission of many air and water borne diseases and food productivity to that part of population which is more susceptible. Studies proves that these changes create ambient surroundings to vector organisms, vector species and pathogenic organisms in transmitting vector and water borne diseases at higher rate (MacMichael, 2003).

There is slight downfall of food production worldwide but, it seemed to be remarkable in many of the food insecure regions such as South Asia, Africa and Central America with an increasing malnutrition population. And with these greenhouse gas concentration in the atmosphere results in depletion of ozone layers, consequently, increasing potential health consequences such as skin-diseases and suppression in immune power. These increased temperatures also increase the production of toxic photochemical smog in urban areas creating bad environment for the local residents and road users (MacMichael, 2003).

However, it is significant that extreme events beyond threshold levels of tolerance will have negative impacts on human health. These impacts can be direct, such as loss of life and injuries and indirect such as loss of food, shelter and infrastructure, contamination of air and water, migrations to other parts of the world.

\subsubsection{Case Study: Africa, Asia, and North America} a) Background

Firstly, Africa is susceptible to climate - sensitive diseases such as cholera, malaria, meningitis and flue-borne diseases due to inter-annual climate variations in East Africa, heavy flooding in arid regions of Kenya, long term droughts Sahel regions and increase in the rodent population in Mozambique, Namibia and Malawi (MacMichael, 2003).

Secondly, many parts of Asia are susceptible to vector-borne diseases due to change in temperature and precipitation patterns periodically. And water-borne diseases resulted by contaminated water in southern parts of Asia spread out at higher rates in warmer climatic conditions. In many cities of China, the mortality of vulnerable people has increased due to rise in maximum daily temperatures beyond $35^{\circ} \mathrm{C}$ over a period of time (MacMichael, 2003).

Thirdly, North America which has a direct impact due to temperature stress and water related disasters. The photochemical smog risk on urban air qualities increased with the rise in temperatures in many parts of North America. Statistical figures show that hundred millions of people lived in areas with undesirable air quality and unacceptable ground level ozone and there were thousands of death cases related to heat in north-east and mid-west America (MacMichael, 2003).

\section{b) Key Vulnerabilities}

The key vulnerabilities to climate change human settlements that are susceptible to certain health outcomes. These populations' vulnerability is influenced by population density, areas' economic development patterns, spatial structure, income standards, food availability, local ambience, educational status, knowledge and awareness levels, age and sex, marital status, health conditions, quality and availability of health services (MacMichael, 2003). The poor, the young and the old are the more sensitive to health hazards.

\section{c) Possible Mitigation and Adaptive measures}

The adverse impact in these areas can thus be avoided or reduce the impacts/ loss with the following adaptive/ mitigative measures.

- The strategies can be of both administrative and legislative i.e., actions taken up by the government bodies or can be of non-governmental organizations or voluntary organizations on basis of advocacy or economic incentives.

- Strategies for income redistribution, full employment opportunities and better basic services.

- Upgrading the environmental management systems, proper awareness programs at local communities.

- Integration of climate, health, human activities into planning process.

- Development of public health infrastructure at local communities.

- Improve monitoring and surveillance systems of health care at local communities.

\section{Costs, Benefits and Ethical arguments of Mitigation and Adaptation}

Due to uncertainties of global climate conditions the costs of adaptation and mitigation are always beyond estimations. The current estimates range from $\$ 3$ billion to $\$ 135$ billion/ year (World bank, 2010). But, the current economic loss due to climate change $\$ 125$ billion/ year. If considering the damage costs of impact on human health, it is much less to put the monetary resources in adaptation and mitigation. It is estimated that total costs of adaptation of one-meter sea level rise by 2100 in Australia would be $\$ 34.54$ billion (Fankhauser, 1995). Hence, therefore, it is must to have adaptation and mitigation costs which are much less than greenhouse gas emission damage costs.

Mitigation and adaptation strategies that are proposed shall meet social justice issues with the reduction in socioeconomic differences and fair participation of local communities and affected groups. These are strategies that target vulnerable groups to the climate changes in order to withstand the upcoming threats and already existing situations. The strategies that include advanced technologies and practices with deep understanding of current and past trends of climate change and human health (Mearns, 2010)

In terms of tackling human health and sea level rise issues of climate change of mitigate strategies - a social justice perspective is being highlighted i.e., there is common goal to 
reduce impact of climate change and varied responsibilities for different actors and groups. And low-carbon economy mitigation strategies play a vital role in curbing down carbon levels of developed, developing and low-developed countries. All these strategies show a significant reduction in greenhouse gas emissions (Mearns, 2010).

In terms of tackling human health and sea level rise issues of climate change on adaptive strategies - local communities and vulnerable groups are given opportunity to participate in preparedness programs and integrated planning process, development of health services and upgrading their environmental managements. The strategies such as income redistribution, full employment generation lead to millennium development goals and reduce the poverty levels. Strategies also can include developing infrastructure at a greater scale to withstand the upcoming pressures (Mearns, 2010).

\section{Conclusion}

The impact of climate change on human settlements is increasing at an alarming rate. There should be spontaneous response from the communities to support government, investors and civil societies to face the catastrophic climate change. Government and investors should spend available resources on mitigation and adaptation, and it would be only effective and successful if there is equitability. Despite adaptation to climate change, there must be diversity on land-use, local organizations and productions, cultural and social values. There should be openness, ethical, equitable and responsiveness among the decision making which can easily solve the local, national and global issues.

\section{References}

[1] Fankhauser, S. (1995). Valuing Climate Change: The Economics of Greenhouse. London: Earth Scan Publications Pvt. Ltd.

[2] Hansjiirgens, B.A. (2008). Economics and Management of Climate Change: Risks, Mitigation and Adaptation. Germany: Springer.

[3] MacMichael, A.C. (2003). Climate Change and Human Health: Risk and Responses. Geneva: World Health Organization.

[4] Mearns, R. N. (2010). New Frontiers of Social Policy: Social Dimensions of Climate Change: Equality and Vulnerability in a Warming World. Washington D.C.: The World Bank.

[5] Pearman, G. (1988). Green House: Planning for Climate Change. Australia: CISRO.

[6] The World Bank. (2009). Climate Change Adaptation. url: http://beta.worldbank.org/overview/climate-changeadaptation. Retrieved on July 10, 2021.

[7] The World Bank. (2009). Climate Change and the World Bank. url: http://beta.worldbank.org/overview. Retrieved on July 01, 2021.

[8] The World Bank. (2009). Climate Change Mitigation. url: http://beta.worldbank.org/overview/climate-changemitigation. Retrieved on July 01, 2021.

[9] The World Bank. (2010). World Development Report 2010: Development and Climate Change. Washington D.C.: The World Bank. 